\title{
Anionic Ligand Exchange in Hoveyda-Grubbs Ruthenium(II) Benzylidenes
}

Kiyotaka Tanaka, ${ }^{*}$ Volker P. W. Böhm, ${ }^{\dagger}$ David Chadwick, ${ }^{\S}$ Michael Röper ${ }^{\dagger}$ and D.

Christopher Braddock

${ }^{*}$ Department of Chemistry, Imperial College London, South Kensington, London SW7 2AZ, UK

${ }^{\S}$ Department of Chemical Engineering, Imperial College London, South Kensington, London SW7 2AZ, UK

${ }^{\dagger}$ Basic Chemicals Research, BASF Aktiengesellschaft, Ludwigshafen, Germany

\section{SUPPORTING INFORMATION}

pS1. SI cover page and index;

pS2. General experimental procedures \& materials;

pS3. Procedure for the preparation of dibromide $\mathbf{6}$, and general protocol for ligand exchanges;

pS4. ${ }^{1} \mathrm{H}$ NMR spectrum $(0-20 \mathrm{ppm})$ of chloride $\mathbf{3}$;

pS5. ${ }^{1} \mathrm{H}$ NMR spectrum $(0-20 \mathrm{ppm})$ of trifluoroacetate 4;

pS6. ${ }^{1} \mathrm{H}$ NMR spectrum $(0-20 \mathrm{ppm})$ of pentafluoroacetate 5;

pS7. ${ }^{1} \mathrm{H}$ NMR spectrum $(0-20 \mathrm{ppm})$ of bromide $\mathbf{6}$;

pS8. ${ }^{13} \mathrm{C}$ NMR spectrum of bromide $\mathbf{6}$;

pS9. MS of bromide 6 and inset of simulated MS isotope pattern of parent ion;

pS10. Time-resolved ${ }^{1} \mathrm{H}$ NMR spectra (16-18 ppm) of ligand exchange of $\mathbf{4}$ with 5 to give 7;

pS11. ${ }^{1} \mathrm{H}$ NMR spectra (0-20 ppm) of ligand exchange of $\mathbf{4}$ with 5 to give $\mathbf{7}$;

pS12. MS of equilibrium mixture of $\mathbf{4}, \mathbf{5} \& \mathbf{7}$ and inset of simulated MS isotope pattern of $\mathbf{1 0}$;

pS13. ${ }^{1} \mathrm{H}$ NMR spectra (16-18 ppm) of ligand exchange of $\mathbf{3}$ with $\mathbf{4}$ to give $\mathbf{8}$;

pS14. ${ }^{1} \mathrm{H}$ NMR spectra $(0-20 \mathrm{ppm})$ of ligand exchange of $\mathbf{3}$ with $\mathbf{4}$ to give $\mathbf{8}$;

pS15. MS of equilibrium mixture of $\mathbf{3}, \mathbf{4} \& \mathbf{8}$ and inset of simulated MS isotope pattern of parent ion of 8 ;

pS16. ${ }^{1} \mathrm{H}$ NMR spectra (16-18 ppm) of ligand exchange of $\mathbf{3}$ with $\mathbf{5}$ to give 10;

pS17. ${ }^{1} \mathrm{H}$ NMR spectra $(0-20 \mathrm{ppm})$ of ligand exchange of $\mathbf{3}$ with $\mathbf{5}$ to give 10;

pS18. MS of equilibrium mixture of $\mathbf{3}, \mathbf{5} \& \mathbf{1 0}$ and inset of simulated MS isotope pattern of parent ion of 10;

pS19. ${ }^{1} \mathrm{H}$ NMR spectra (16-18 ppm) of ligand exchange of $\mathbf{4}$ with $\mathbf{6}$ to give 12;

pS20. ${ }^{1} \mathrm{H}$ NMR spectra $(0-20 \mathrm{ppm})$ of ligand exchange of $\mathbf{4}$ with $\mathbf{6}$ to give 12;

pS21. MS of equilibrium mixture of 4,6 \& 12 and inset of simulated MS isotope pattern of parent ion of 12;

pS22. ${ }^{1} \mathrm{H}$ NMR spectra (16-18 ppm) of ligand exchange of 5 with $\mathbf{6}$ to give $\mathbf{9}$;

pS23. ${ }^{1} \mathrm{H}$ NMR spectra (0-20 ppm) of ligand exchange of 5 with $\mathbf{6}$ to give $\mathbf{9}$;

pS24. MS of equilibrium mixture of 5, $6 \& \mathbf{9}$ and inset of simulated MS isotope pattern of parent ion of 9;

pS25. ${ }^{1} \mathrm{H}$ NMR spectra (16-18 ppm) of ligand exchange of 3 with $\mathbf{6}$ to give 11;

pS26. ${ }^{1} \mathrm{H}$ NMR spectra $(0-20 \mathrm{ppm})$ of ligand exchange of $\mathbf{3}$ with $\mathbf{6}$ to give 11;

pS27. MS of equilibrium mixture of $\mathbf{3}, \mathbf{6} \& \mathbf{1 1}$ and inset of simulated MS isotope pattern of parent ion of 11; 


\section{General.}

Infra-red spectra were recorded on a Mattson 5000 FTIR spectrometer with Graseby Specac attachment. Only selected absorbencies $\left(\square_{\max }\right)$ are reported. Microanalyses were determined in the microanalytical laboratories at the Department of Health and Human Sciences, London Metropolitan University. Mass spectra were obtained, using fast atom bombardment (FAB+) at the Department of Chemistry, Imperial College London.

Proton magnetic resonance $\left({ }^{1} \mathrm{H}\right.$ NMR) spectra were recorded on a JEOL 270 spectrometer, in $d_{8}$-THF, at $300 \mathrm{~K}$, unless otherwise stated, and are reported as follows: chemical shift $\mathrm{a}(\mathrm{ppm})(\mathrm{number}$ of protons, multiplicity, coupling constant $J(\mathrm{~Hz})$, assignment). The coupling constants are quoted to the nearest $0.5 \mathrm{~Hz}$ ( $\mathrm{s}=$ singlet, $\mathrm{d}=$ doublet, $\mathrm{t}$ - triplet, $\mathrm{q}=$ quartet, $\mathrm{m}=$ multiplet, $\mathrm{br}=$ broad, $\mathrm{ap}=$ apparent). The residual protic solvent $d_{8}$-THF $\left(\square_{\mathrm{H}}=1.72 \mathrm{ppm}\right)$ was used as the internal reference. ${ }^{13} \mathrm{C}$ NMR were recorded in $d_{8}$ THF at $298 \mathrm{~K}$, unless otherwise stated, at $68 \mathrm{MHz}$ on the same spectrometer with broadband decoupling. The resonance of $d_{8}-\mathrm{THF}\left(\square_{\mathrm{C}}=24.21 \mathrm{ppm}\right)$ was used as the internal reference. The software package used was MestRE-C Version 3.9. For those cases in which an inseparable mixture of compounds was produced, the data reported were obtained on the mixture.

\section{Materials.}

THF $\left(\mathrm{K}, \mathrm{Ph}_{2} \mathrm{C}=\mathrm{O}\right)$ and $\mathrm{CH}_{2} \mathrm{Cl}_{2}\left(\mathrm{CaH}_{2}\right)$ were distilled under nitrogen immediately before use. "Buchmeiser-Hoveyda-Grubbs II" benzylidene 4 (reference 4 in the paper) and bispentafluoropropanoate homologue 5 (reference $8 \mathrm{c}$ in the paper) were prepared according to the literature procedures using the respective silver perfluorocarboxylates. Alternative preparations utilising free trifluoroacetic acid in conjunction with silver(I) tetrafluoroborate, and separately from lead(II) trifluoroacetate are given below. All other reagents and solvents were purchased from commercial sources and used as received. 


\section{Preparation of benzylidene 4 with lead(II) trifluoroacetate.}

Benzylidene 3 ( $27.57 \mathrm{mg}, 0.044 \mathrm{mmol}$ ) was shaken in the dark for 3 days with lead(II) trifluoroacetate (19.06 mg, $0.044 \mathrm{mmol}, 1.0$ equiv.) in $0.6 \mathrm{ml} \mathrm{CH}_{2} \mathrm{Cl}_{2}$. The dark green solution turns brown then lilac blue, with a fine white precipitate, which was removed by gravity filtration with the aid of an additional $0.2 \mathrm{ml} \mathrm{CH}_{2} \mathrm{Cl}_{2}$. The product bis-acetate benzylidene 4 was characterised by ${ }^{1} \mathrm{H}-\mathrm{NMR}$ $\left(\mathrm{CD}_{2} \mathrm{Cl}_{2}\right)$ (17.45ppm 95\% product, $17.03 \mathrm{ppm} 5 \%$ mono-intermediate, $16.50 \mathrm{ppm} 0 \%$ starting material). The spectroscopic data was identical to that previously reported for 4 (reference 4 in the paper).

\section{Preparation of dibromide 6.}

Benzylidene 3 (100 mg, $0.16 \mathrm{mmol}$ ) was stirred with $\mathrm{LiBr}$ (300 mg, 22 equiv.) in THF (20 mL) for 16 $\mathrm{h}$. The solvent was removed by evaporation and the residue placed under vacuum $(0.1 \mathrm{mmHg}, 12 \mathrm{~h})$ and then suspended in $\mathrm{CH}_{2} \mathrm{Cl}_{2}(20 \mathrm{~mL})$. The insoluble white salts $(\mathrm{LiBr}$ and $\mathrm{LiCl})$ were removed by filtration to give a dark green filtrate. The solvent was evaporated. This protocol was repeated with two more batches of $\mathrm{LiBr}(300 \mathrm{mg})$, and before the final evaporation the organic solution was washed with water $(2 \times 20 \mathrm{~mL})$. The solvent was removed by evaporation to give dibromide $\mathbf{6}(114 \mathrm{mg}, 100 \%)$ as a dark green solid. m.p. decomp $215{ }^{\circ} \mathrm{C},{ }^{1} \mathrm{H}$ NMR (270 MHz, $d_{8}$-THF): 16.25 (s, 1H, Ru=CHAr), 7.52 (t, $1 \mathrm{H}$, aromatic $\mathrm{CH}), 7.14(\mathrm{~m}, 1 \mathrm{H}$, aromatic $\mathrm{CH}), 7.03(\mathrm{~s}, 4 \mathrm{H}$, mesityl aromatic $\mathrm{CH}), 6.91(\mathrm{~d}, 1 \mathrm{H}$, aromatic $\mathrm{CH}$ ), $6.78(\mathrm{~d}$, aromatic $\mathrm{CH}), 4.95$ (septet, $\left.J=6.3 \mathrm{~Hz}, 1 \mathrm{H},\left(\mathrm{CH}_{3}\right)_{2} \mathrm{CHOAr}\right), 4.14(\mathrm{~s}, 4 \mathrm{H}$, $\left.\mathrm{N}\left(\mathrm{CH}_{2}\right)_{2} \mathrm{~N}\right), 2.31-2.57$ (m, 18H, mesityl-CH3), 1.32 (d, $\left.\left(\mathrm{CH}_{3}\right)_{2} \mathrm{CHOAr}\right) . \mathrm{m} / z$ (FAB+) Calcd. 708 (4.9), 709 (1.8), 710 (11.5), 711 (15.3), 712 (23.9), 713 (44.8), 714 (66.1), 715 (61.4), 716 (100.0), 717 (47.0), 718 (69.8), 719 (22.9), 720 (19.7), 721 (6.2), 722 (1.1). Found; 708 (3.5), 709 (0.8), $710(0.8)$, 711 (13.5), 712 (15.4), 713 (23.1), 714 (43.1), 715 (61.5), 716 (100), 717 (53.8), 718 (68.5), 719 (23.1), 720 (18.5), 721 (5.4), 722 (2.7). Microanalysis. Calcd: C, 52.04; H, 5.35; N, 3.92; Found: C, 51.97; H, 5.29; N, 3.86 .

\section{General procedure for ${ }^{1} \mathrm{H}$ NMR-monitored anionic ligand exchange between ruthenium benzylidenes 3-6.}

$\mathrm{RuX}_{2}\left(\mathrm{IMesH}_{2}\right)\left(=\mathrm{CH}-2-(2-\mathrm{PrO}) \mathrm{C}_{6} \mathrm{H}_{4}\right)\left(0.020 \mathrm{mmol}, 1.0\right.$ eq.; $\mathrm{X}=\mathrm{Cl}, \mathrm{Br}, \mathrm{CF}_{3} \mathrm{CO}_{2}$ or $\left.\mathrm{C}_{2} \mathrm{~F}_{5} \mathrm{CO}_{2}\right)$ and $\mathrm{RuX}_{2}\left(\mathrm{IMesH}_{2}\right)\left(=\mathrm{CH}-2-(2-\mathrm{PrO}) \mathrm{C}_{6} \mathrm{H}_{4}\right)\left(0.020 \mathrm{mmol}, 1.0\right.$ eq.; $\mathrm{Y}=\mathrm{Cl}, \mathrm{Br}, \mathrm{CF}_{3} \mathrm{CO}_{2}$ or $\mathrm{C}_{2} \mathrm{~F}_{5} \mathrm{CO}_{2}$ where $\mathrm{Y}$ $\neq \mathrm{X}$ ) were added to an NMR tube at $\mathrm{t}_{0}$ in $d_{8}$-THF $(0.60 \mathrm{~mL})$ at $298 \mathrm{~K}$. The total ruthenium benzylidene concentration was constant at $0.067 \mathrm{M}$. The exchange reaction was monitored by ${ }^{1} \mathrm{H}$-NMR using residual $d_{7}$-THF as an internal standard, integrating the relevant benzylidene signals between 16-18 ppm. 
${ }^{1} \mathrm{H}$ NMR spectrum of $\mathbf{3}$

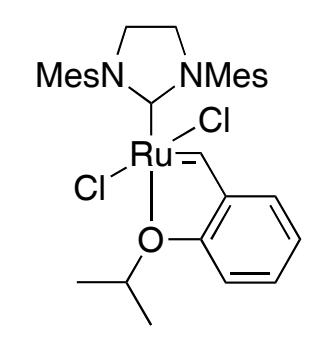




\section{${ }^{1} \mathrm{H}$ NMR spectrum of 4}
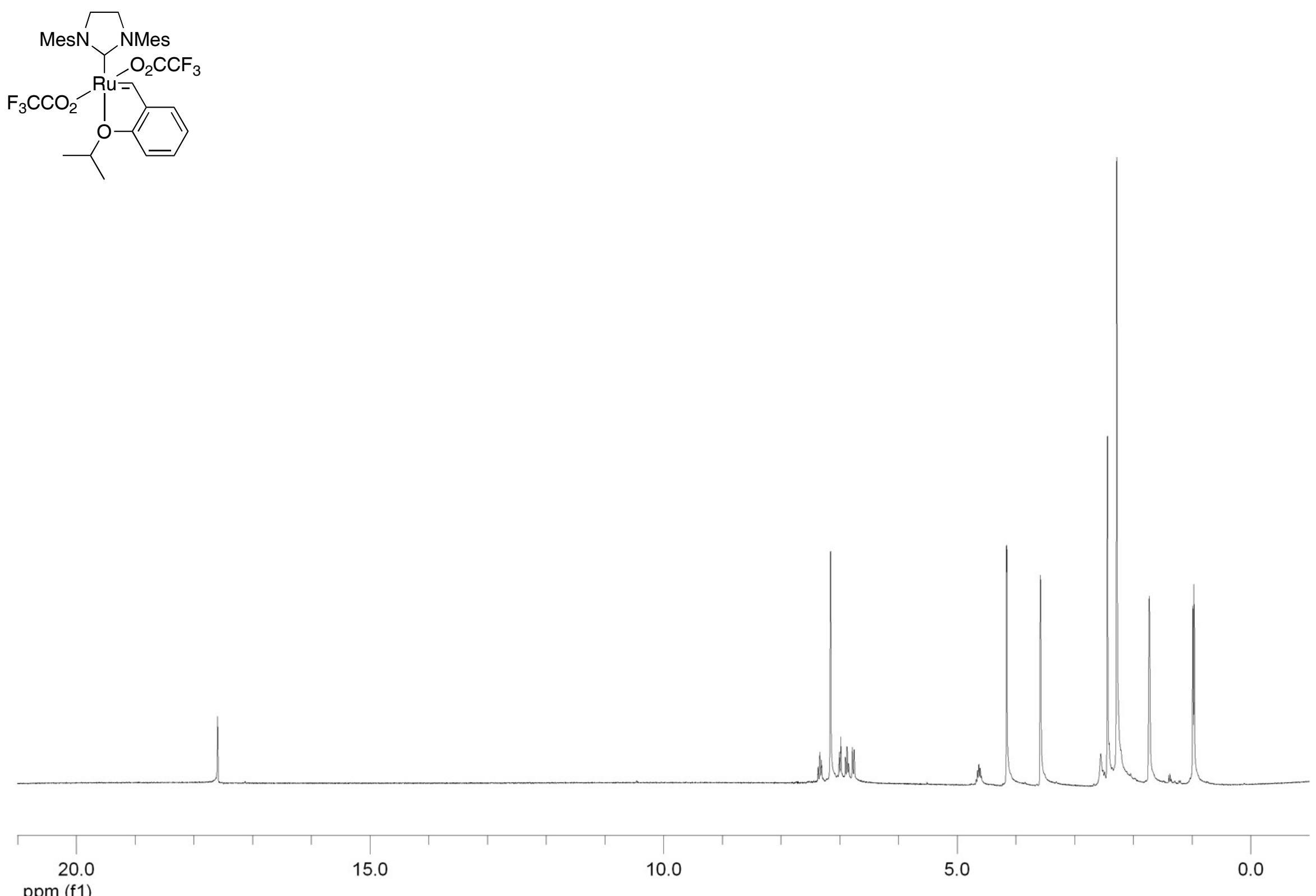
${ }^{1} \mathrm{H}$ NMR spectrum of $\mathbf{5}$
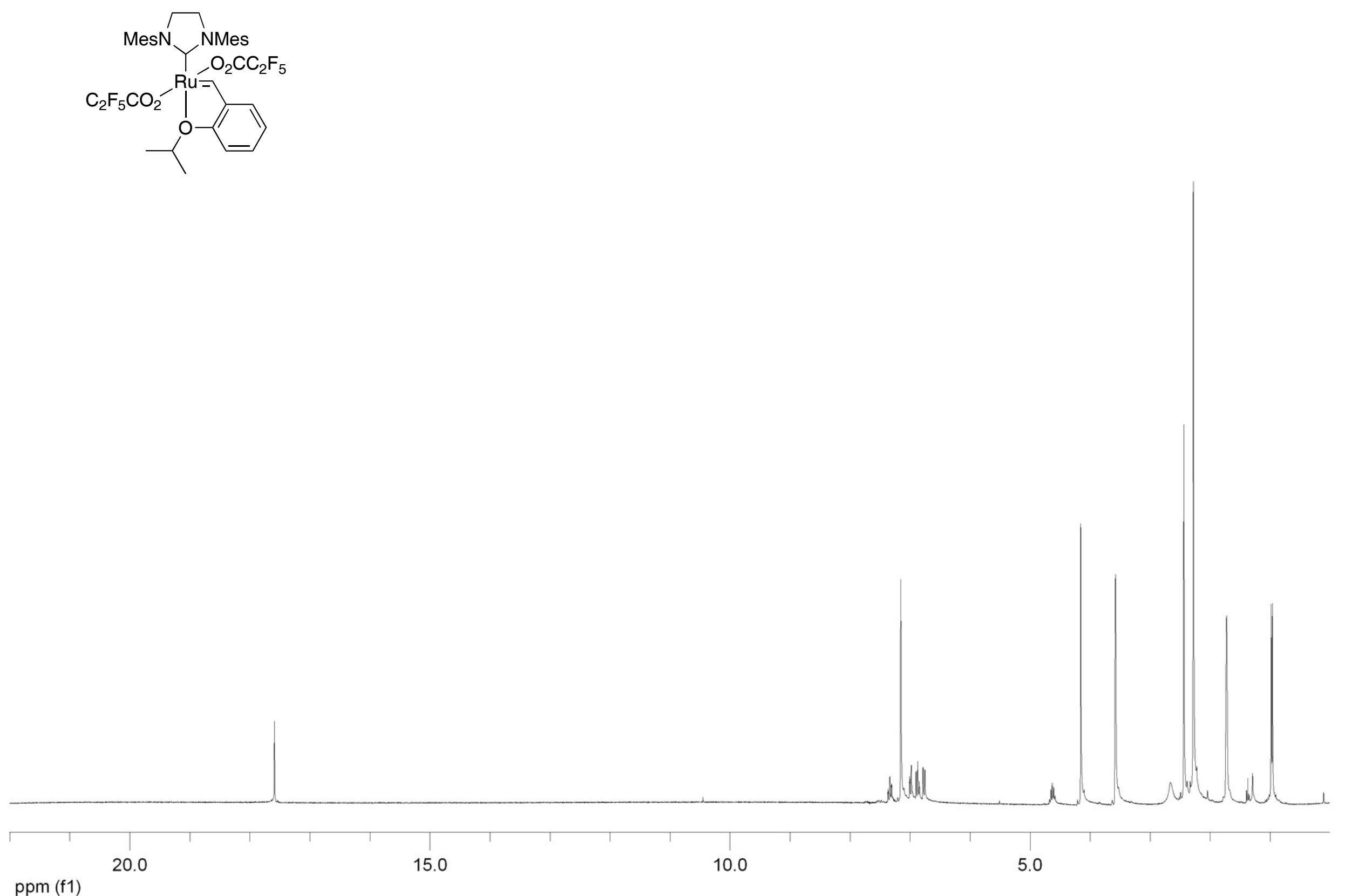
${ }^{1} \mathrm{H}$ NMR spectrum of 6
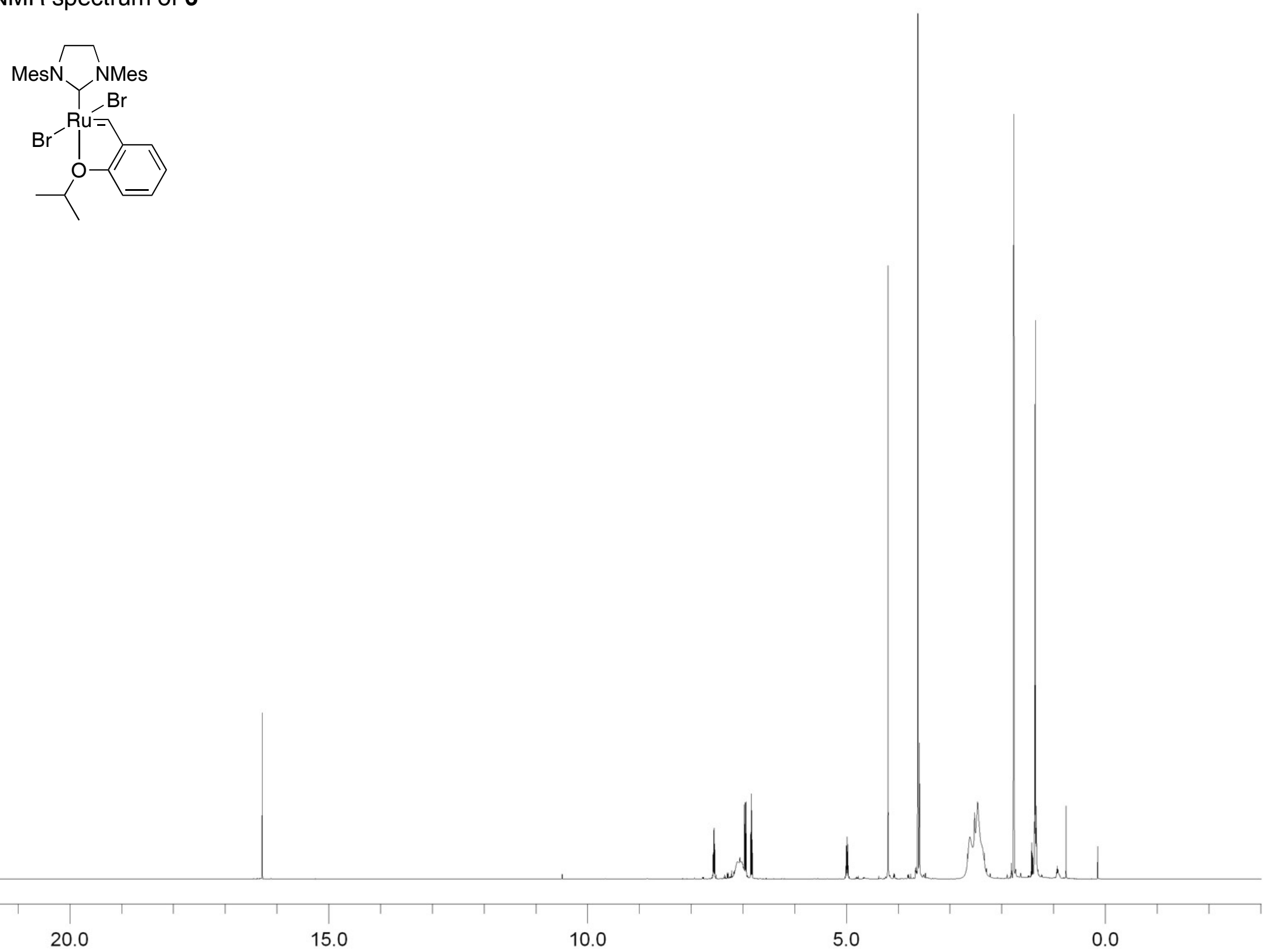
${ }^{13} \mathrm{C}$ NMR spectrum of 6

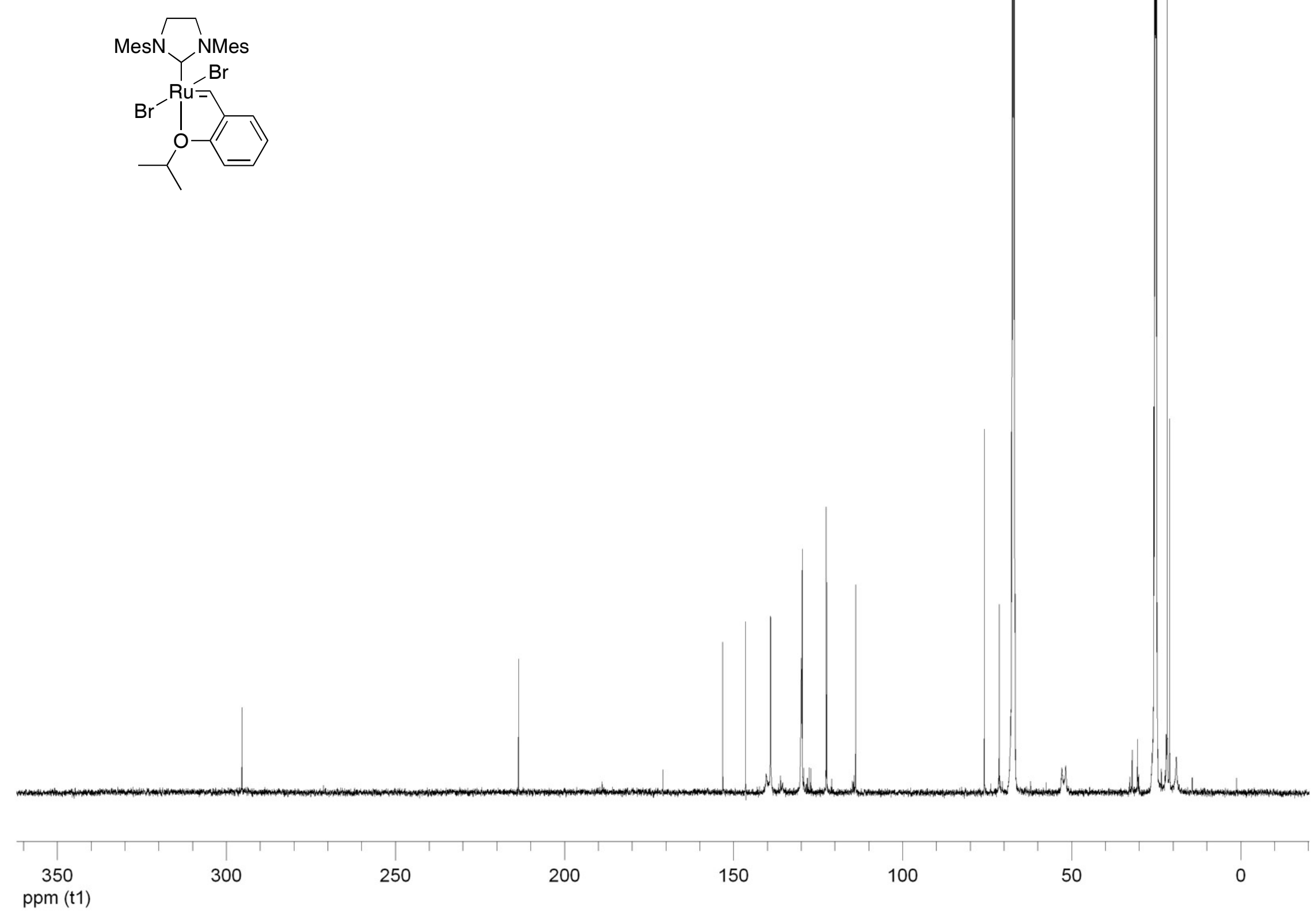


MS of 6 and inset of simulated MS isotope pattern of parent ion

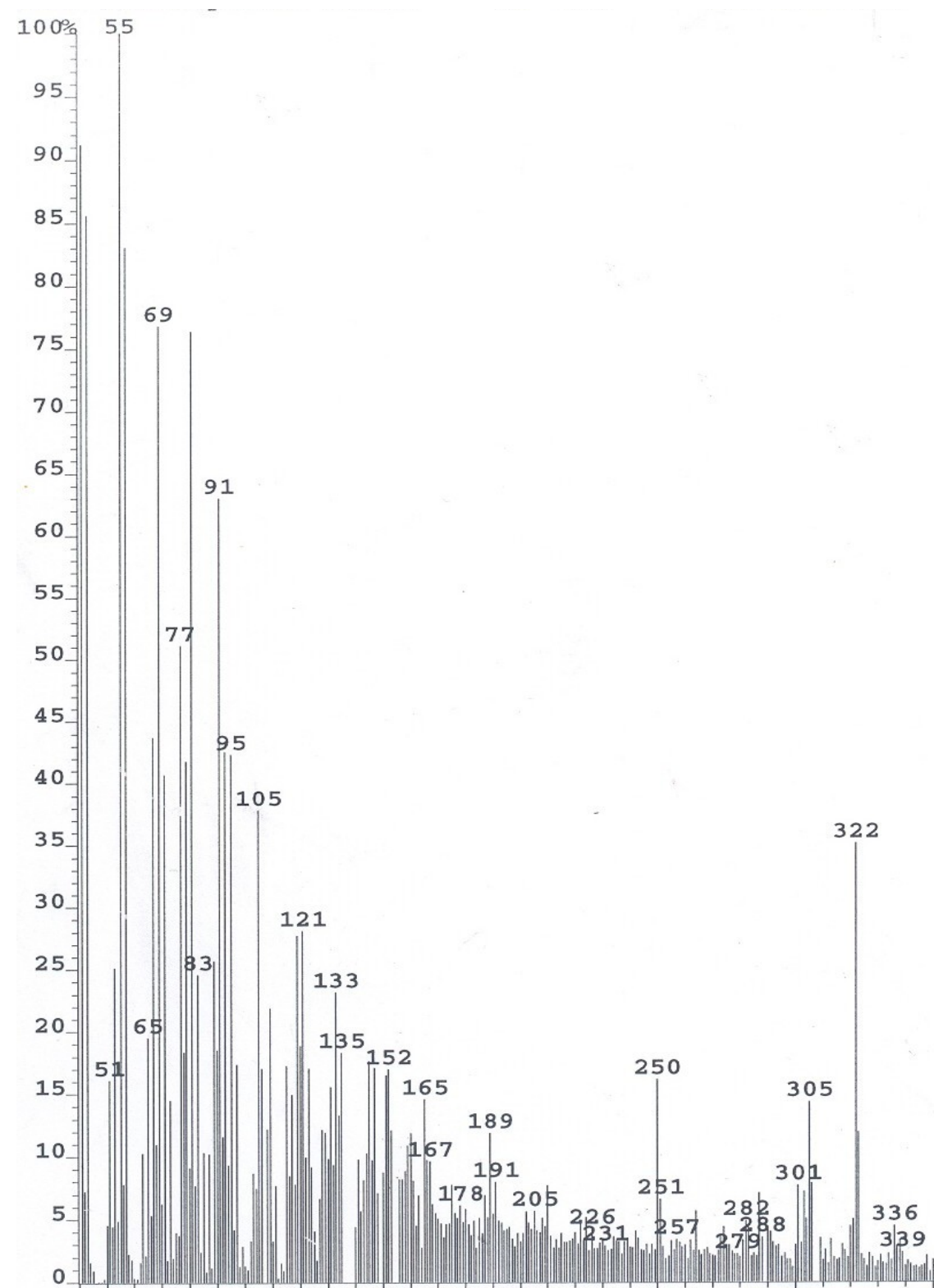

$\mathrm{Br}_{2}[\mathrm{Ru}]$
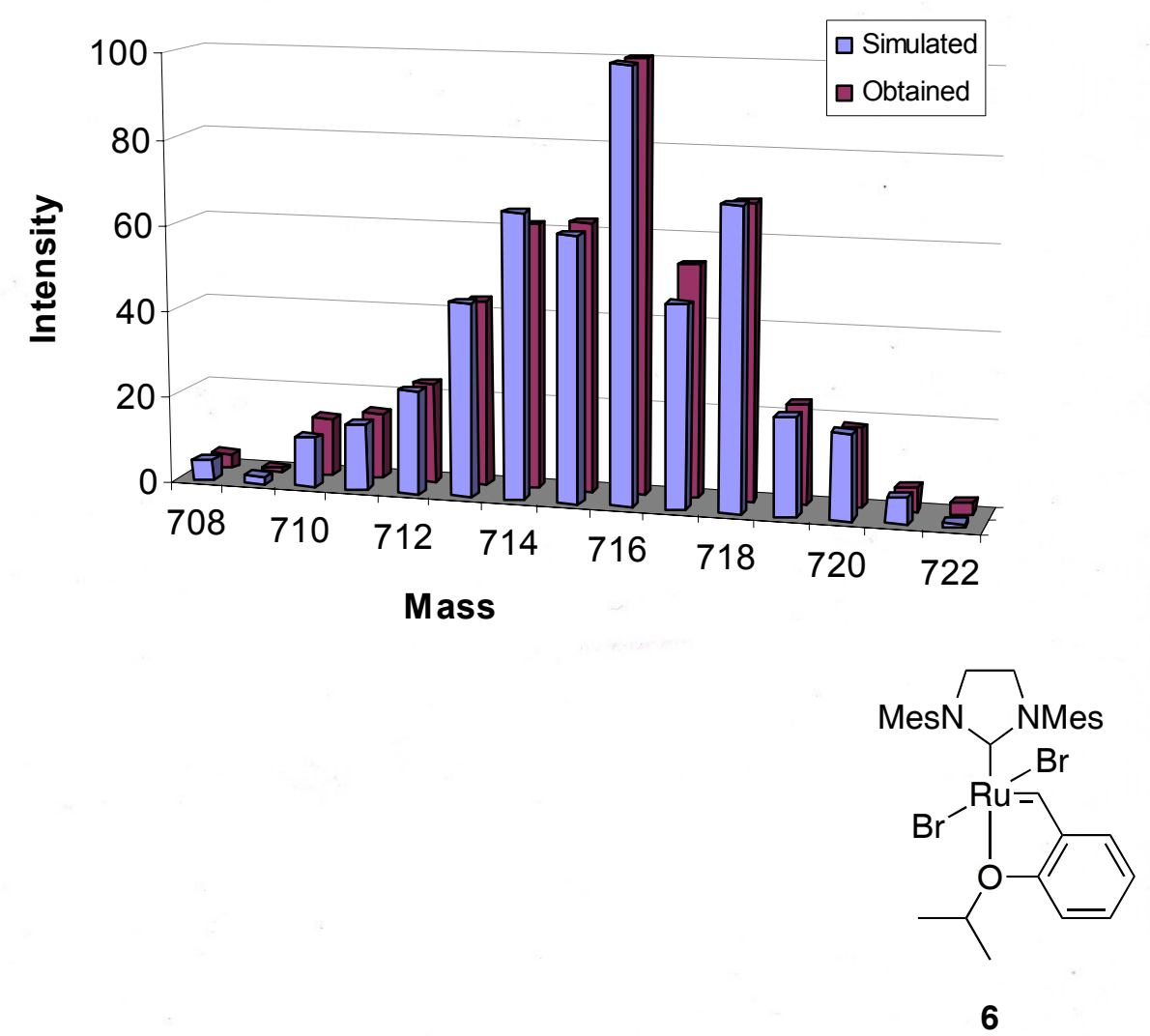

$2 B r$
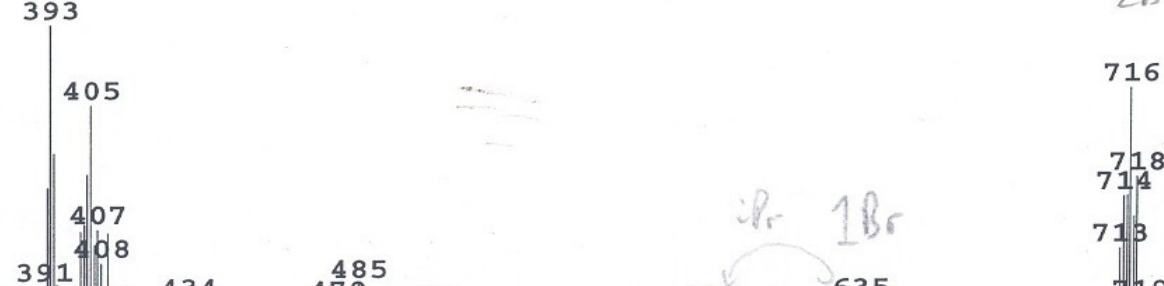

391.434

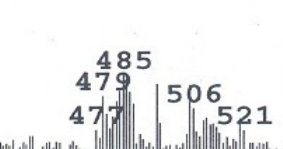

00450

500

550

550 
Ligand exchange between 4 and 5 to give 7

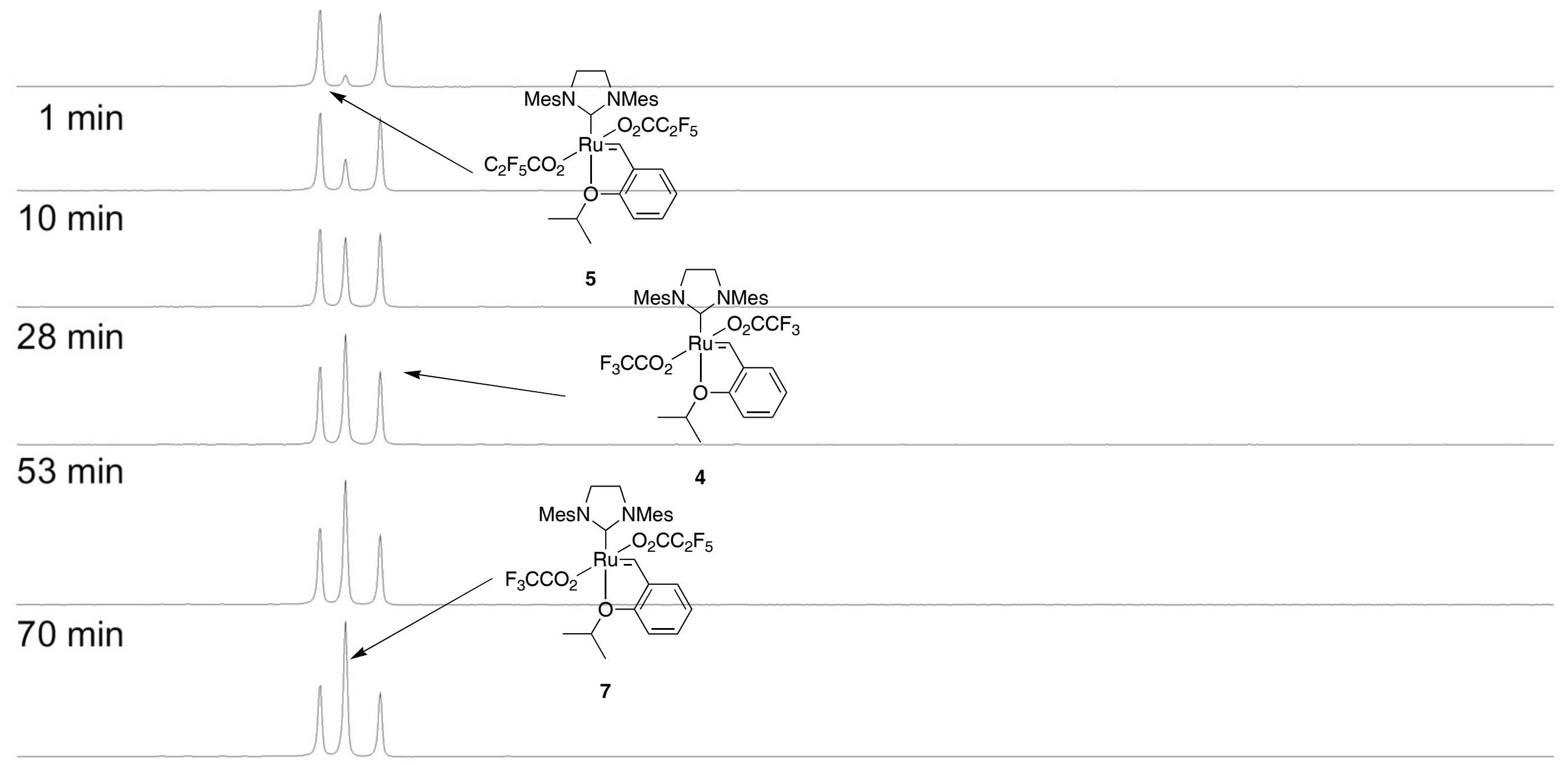

\section{$114 \min$}

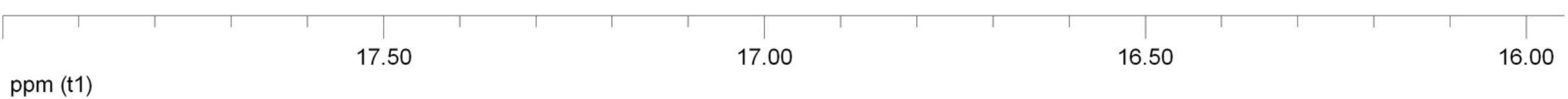


Equilibrium mixture of ligand exchange between $\mathbf{4}$ and $\mathbf{5}$ to give $\mathbf{7}$

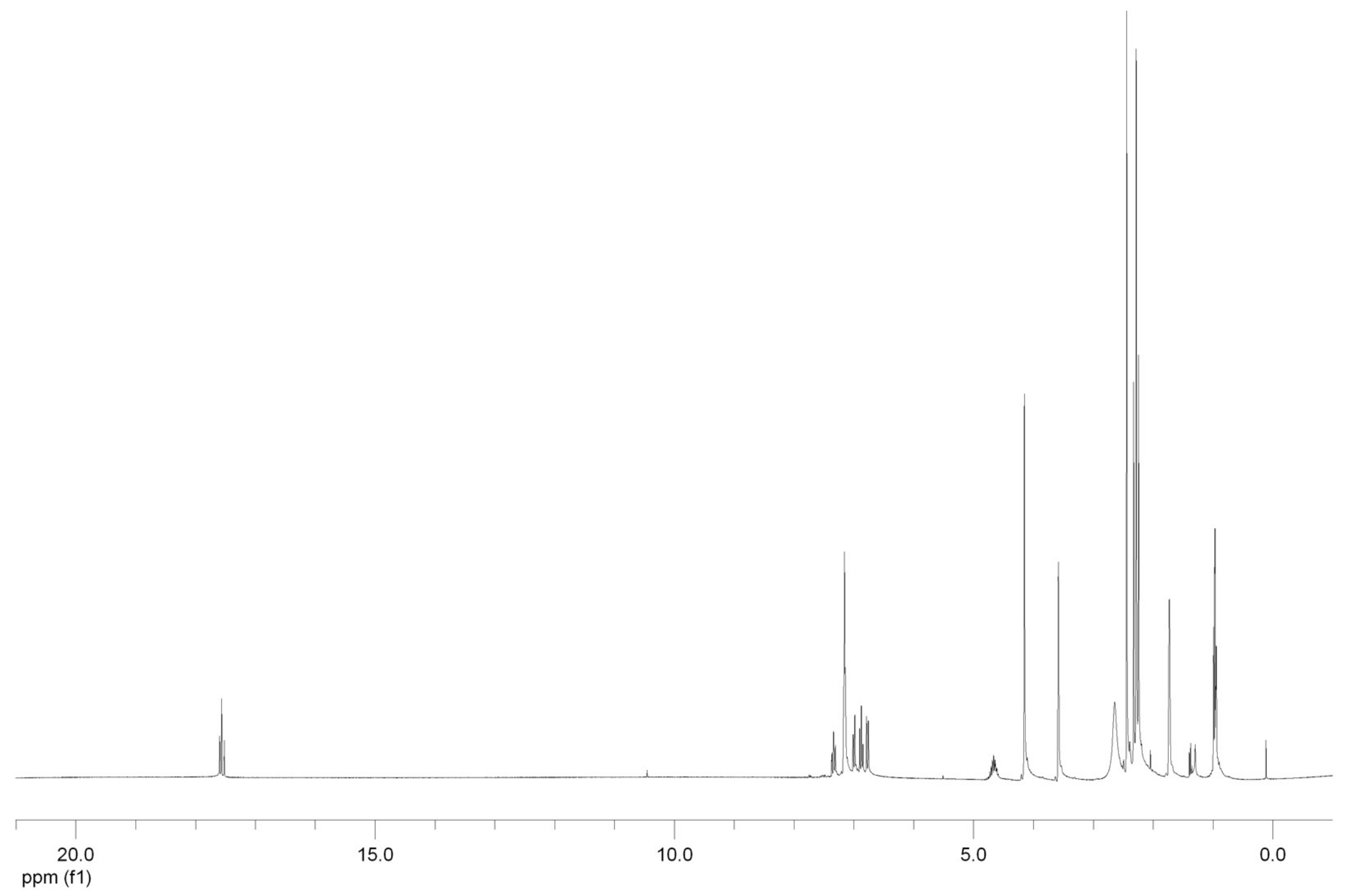


MS of equilibrium mixture of $\mathbf{4 , 5}$ and $\mathbf{7}$ and inset of simulated MS isotope pattern of parent ion of $\mathbf{7}$ as81580 $2(0.610) \mathrm{Cm}(2: 7)$
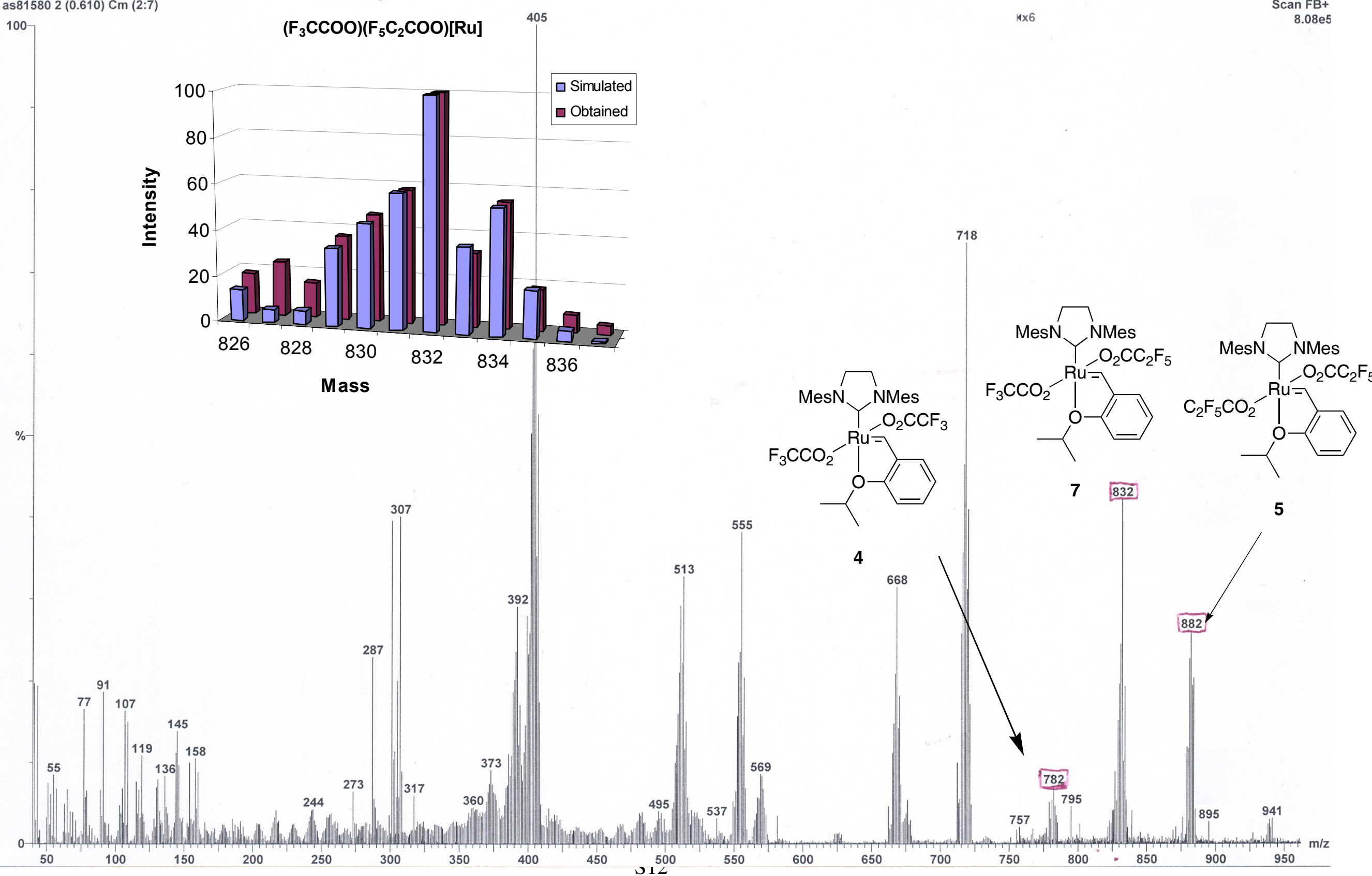
Ligand exchange between $\mathbf{3}$ and $\mathbf{4}$ to give $\mathbf{8}$

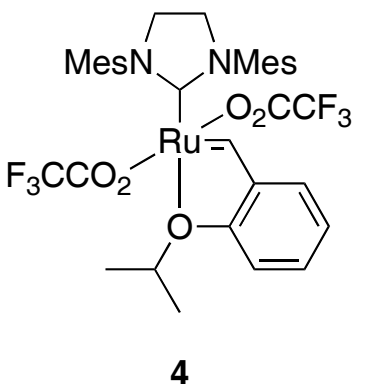

4

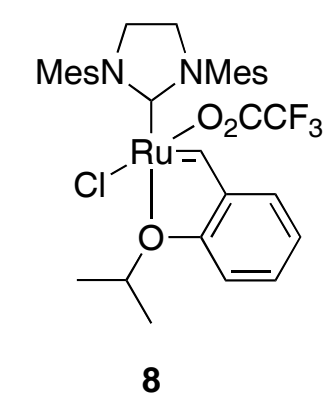

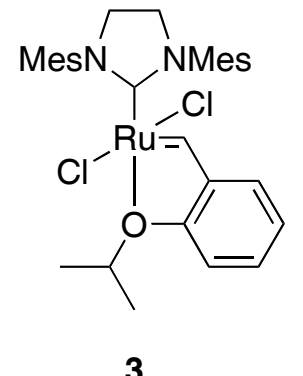

3

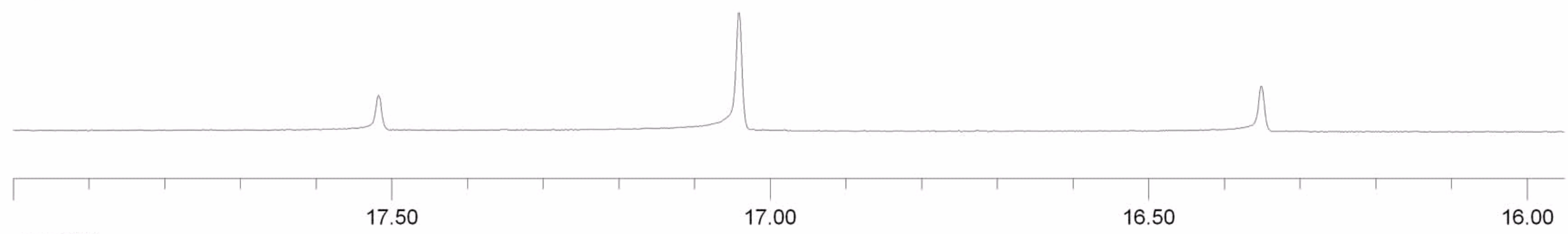

ppm (f1) 


\section{Equilibrium mixture of ligand exchange between $\mathbf{3}$ and $\mathbf{4}$ to give $\mathbf{8}$}

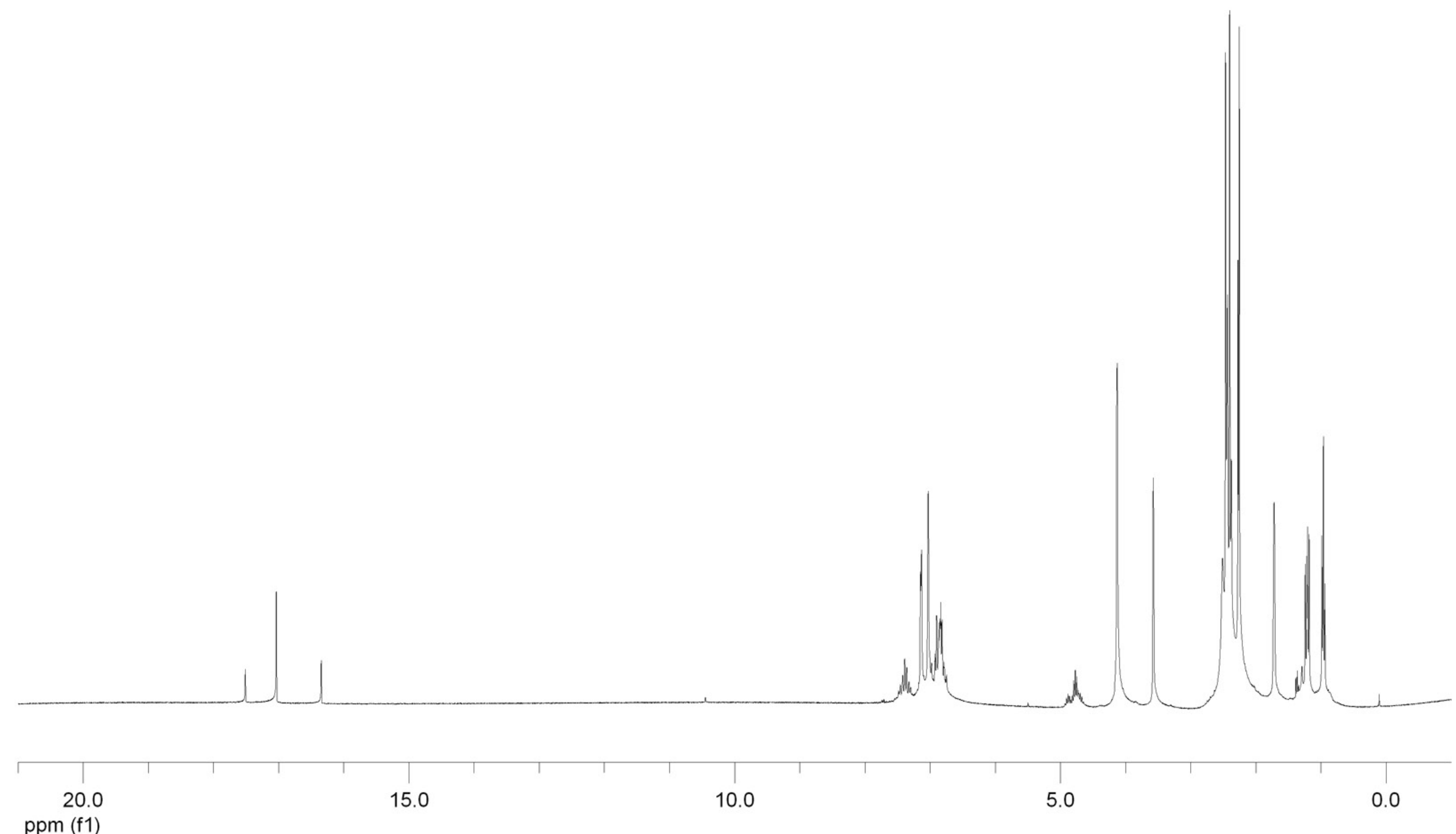




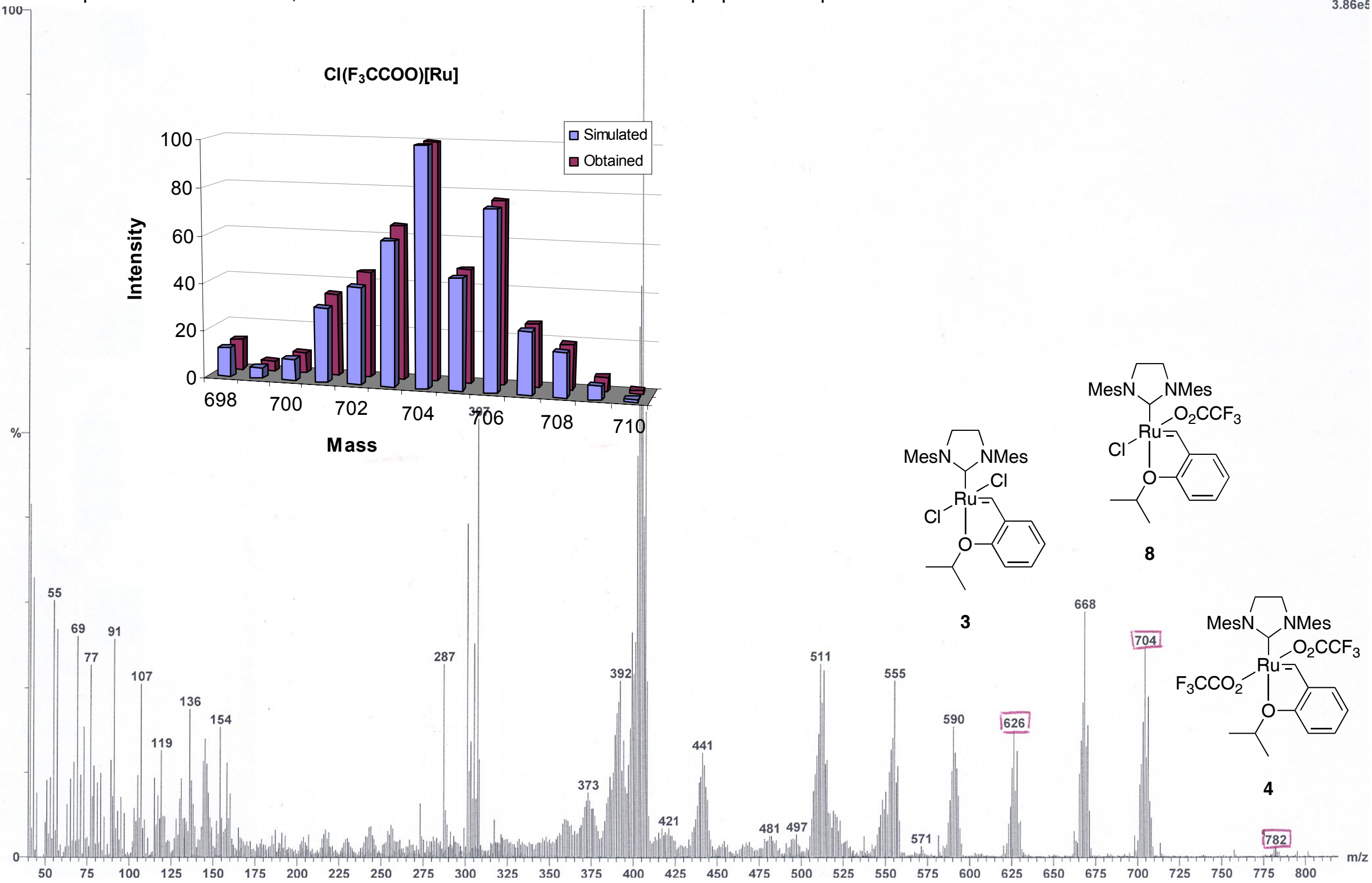


Ligand exchange between $\mathbf{3}$ and $\mathbf{5}$ to give $\mathbf{1 0}$

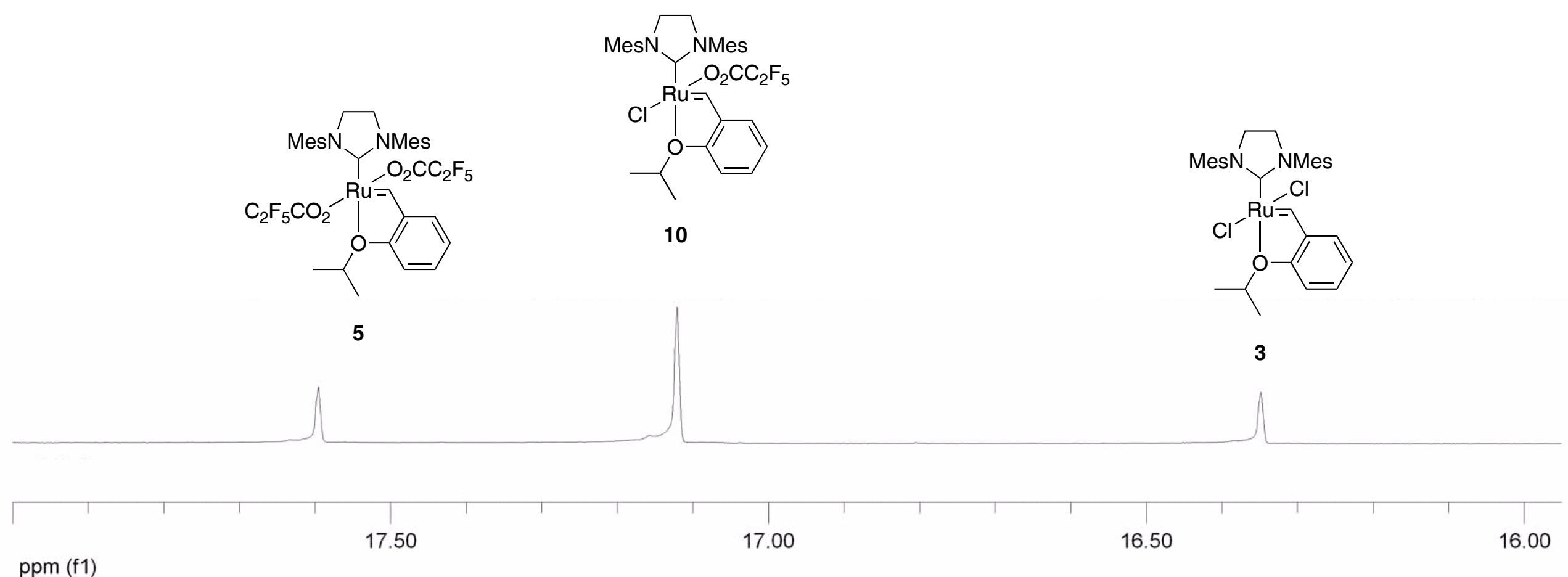


Equilibrium mixture of ligand exchange between 3 and 5 to give 10

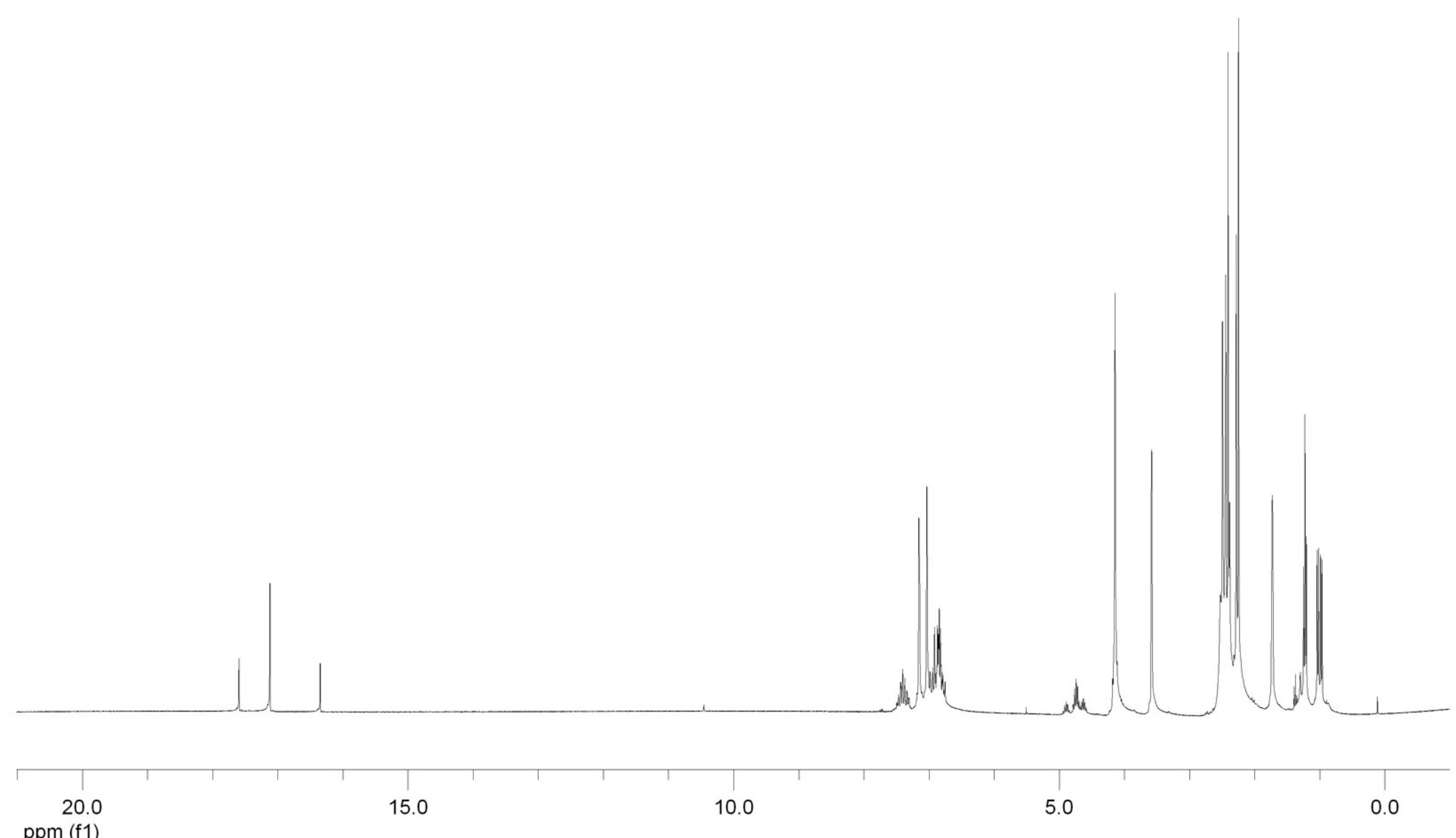


MS of equilibrium mixture of 3, $\mathbf{5}$ and $\mathbf{1 0}$ and inset of simulated MS isotope pattern of parent ion of $\mathbf{1 0}$

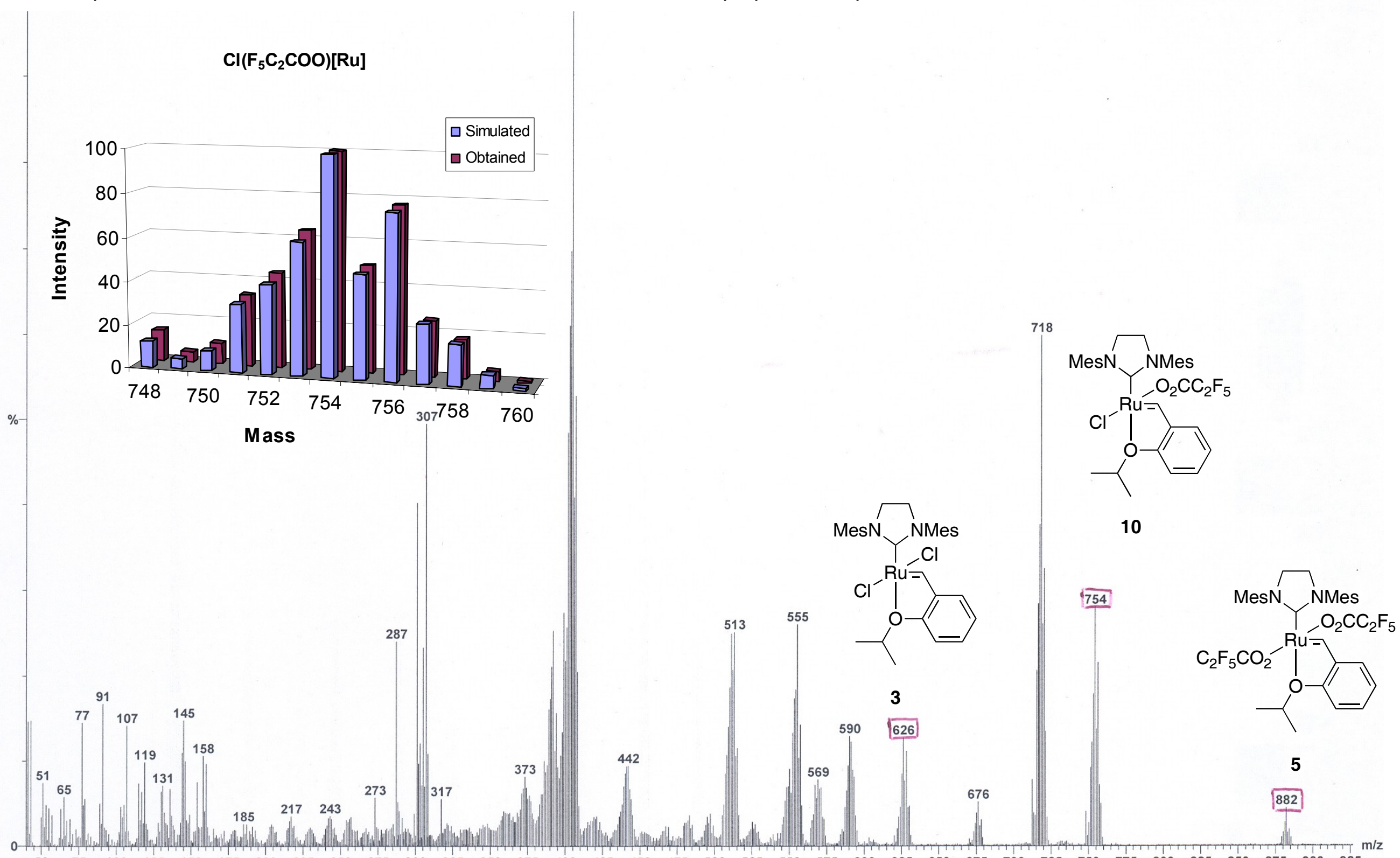

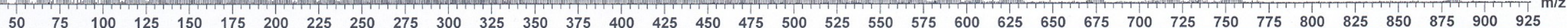


Ligand exchange between 4 and 6 to give 12
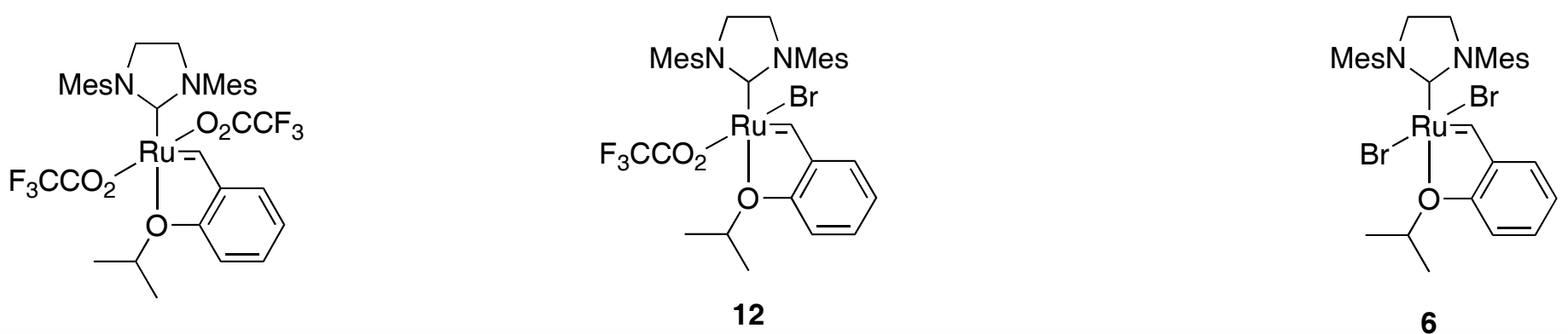

12

6

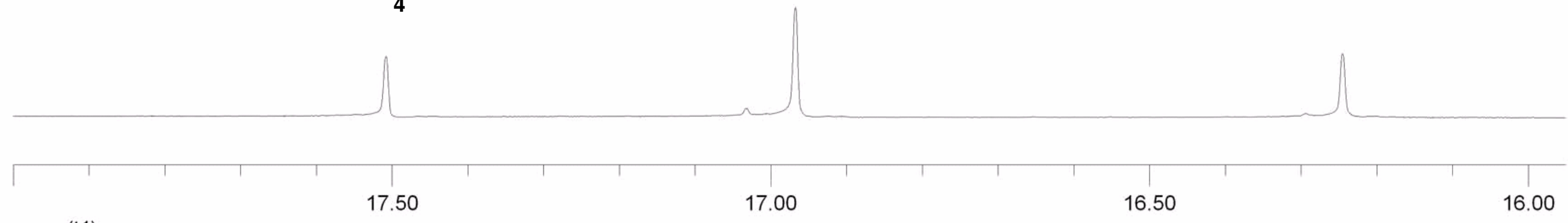

ppm (t1) 


\section{Equilibrium mixture of ligand exchange between 4 and 6 to give 12}

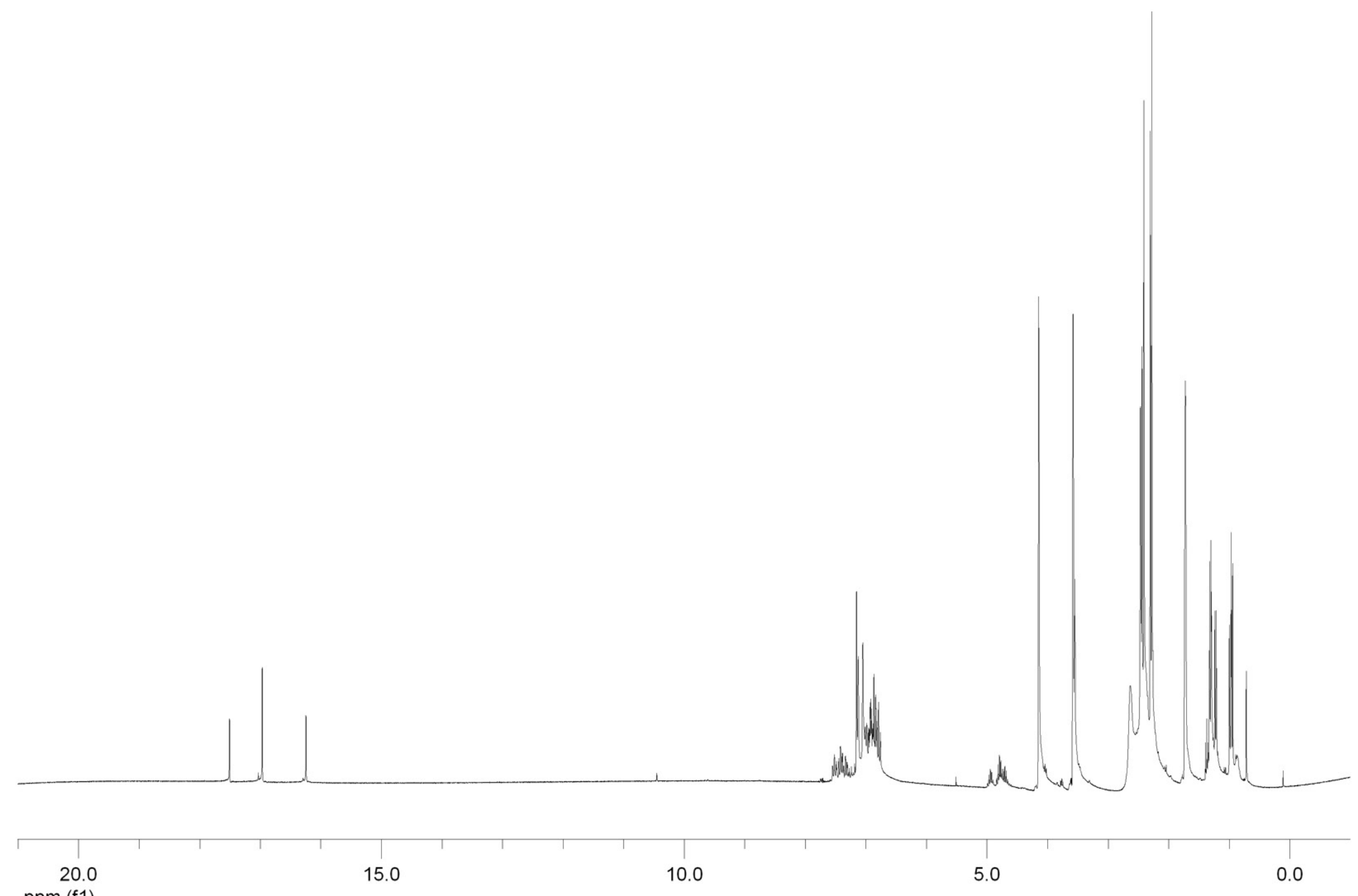

ppm (f1) 
$\operatorname{Br}\left(\mathrm{F}_{3} \mathrm{CCOO}\right)[\mathrm{Ru}]$

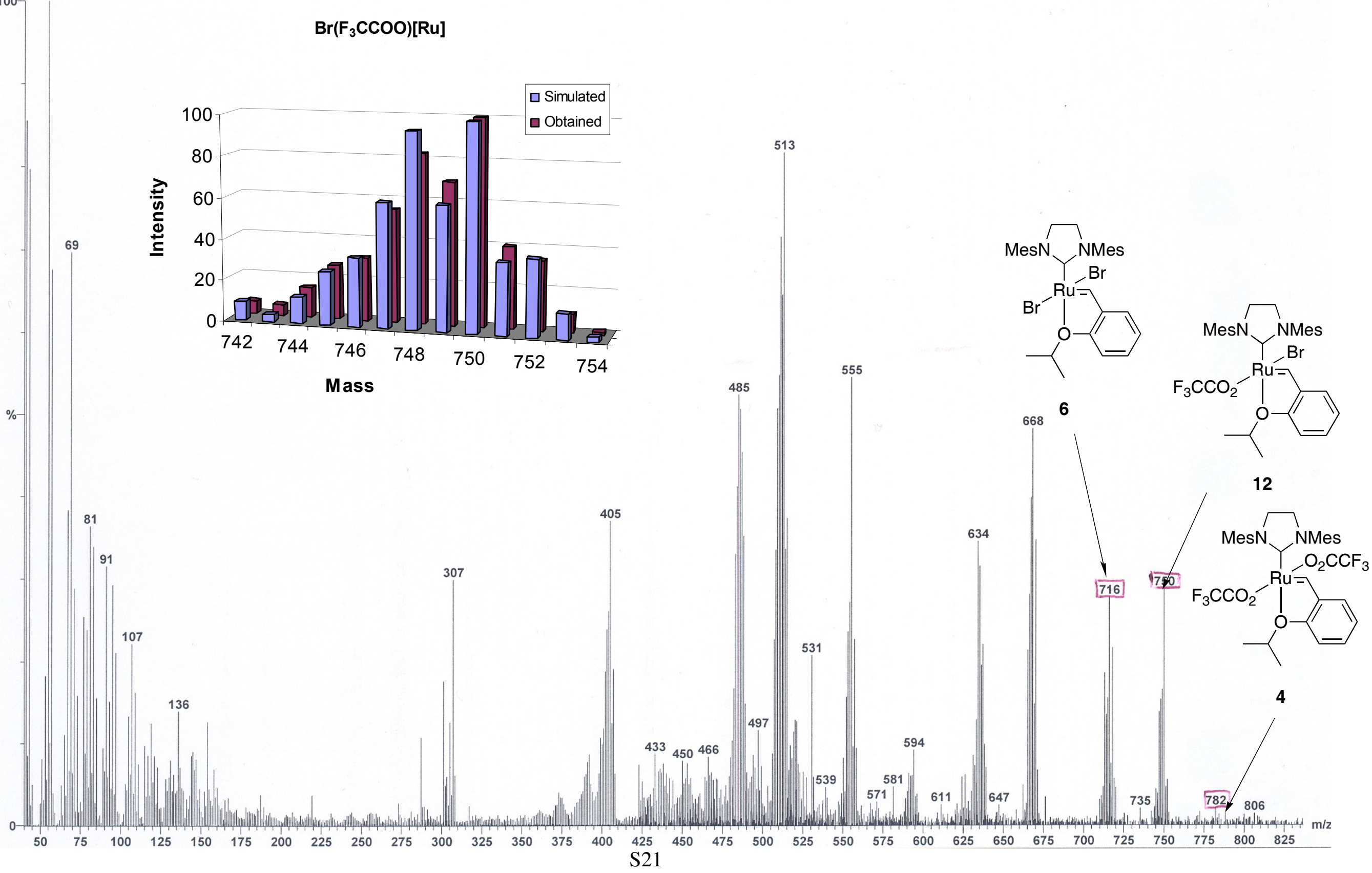


Ligand exchange between 5 and $\mathbf{6}$ to give $\mathbf{9}$
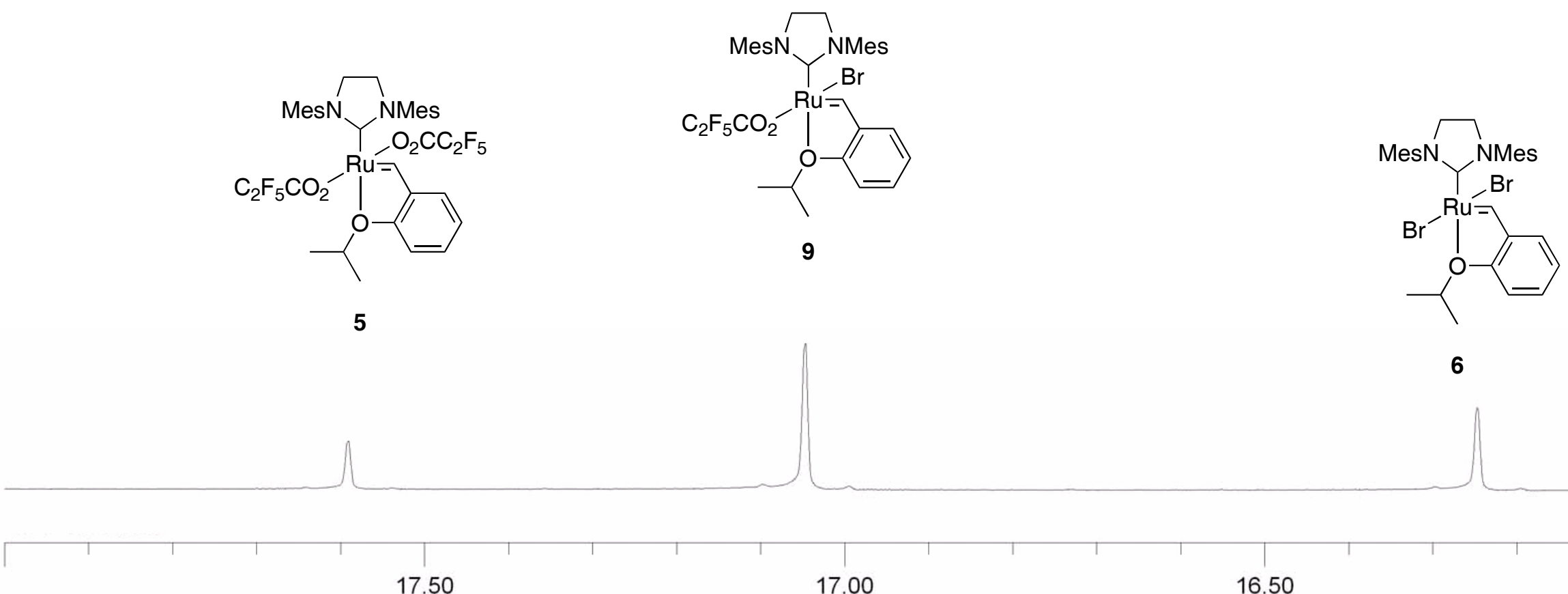

17.00

16.50

16.00

ppm (t1) 
Equilibrium mixture of ligand exchange between $\mathbf{5}$ and $\mathbf{6}$ to give $\mathbf{9}$

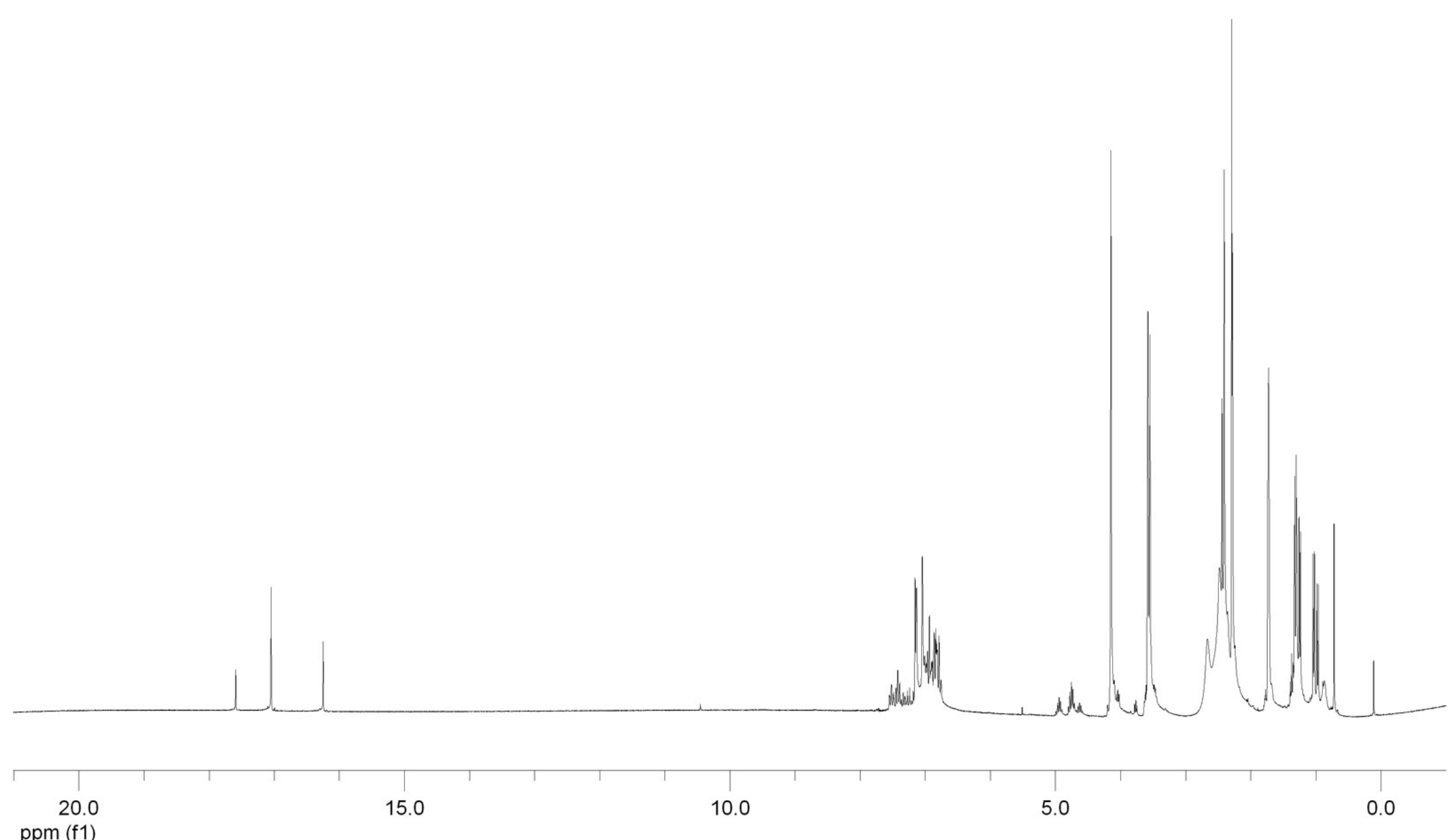


MS of equilibrium mixture of 5, 6 and $\mathbf{9}$ and inset of simulated MS isotope pattern of parent ion of 9 as81577 1 (0.407)

$100-$

$\mathrm{Br}\left(\mathrm{F}_{5} \mathrm{C}_{2} \mathrm{COO}\right)[\mathrm{Ru}]$

405

4x6
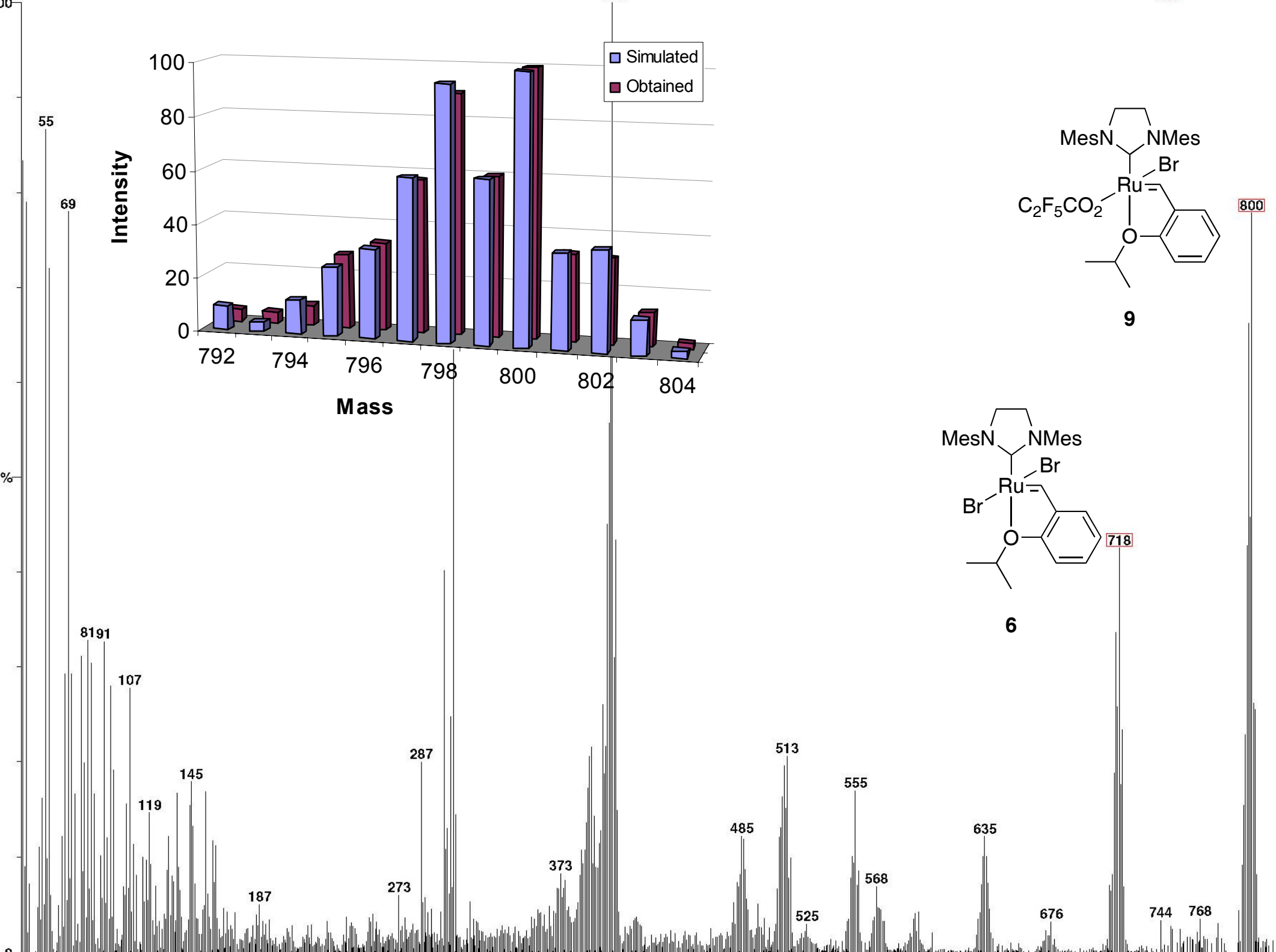
Ligand exchange between 3 and 6 to give 11 (10 hours)

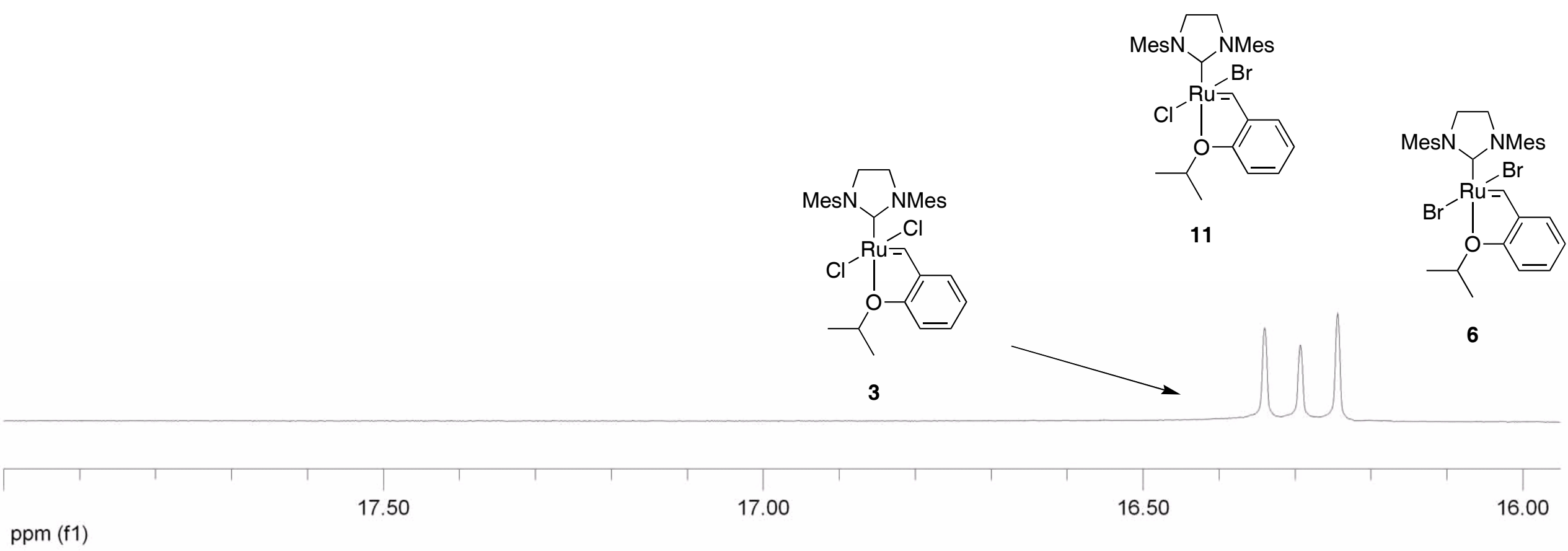


Ligand exchange between 3 and 6 to give 11 (10 hours)

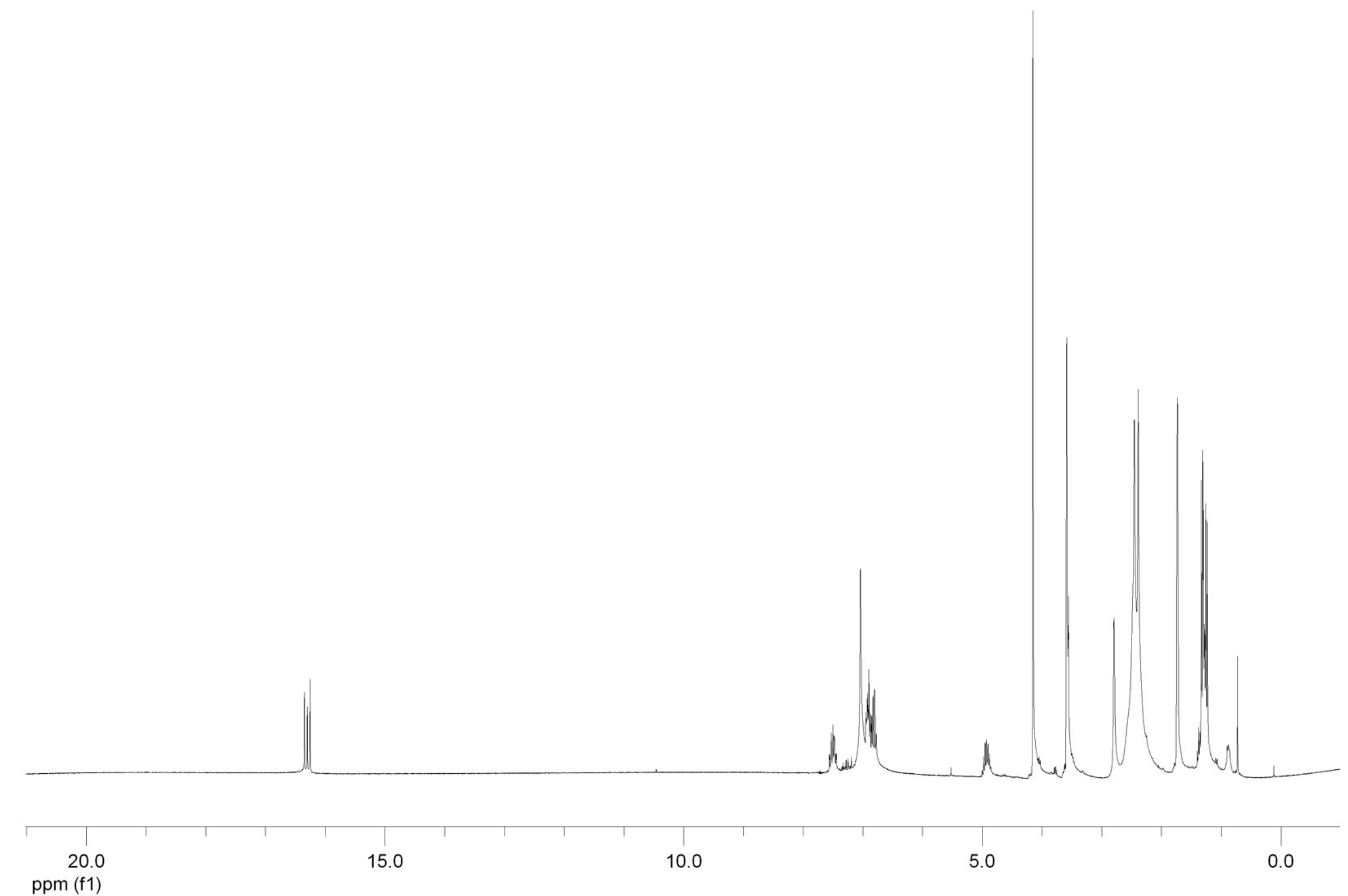


MS of equilibrium mixture of 3, 6 and 11 and inset of simulated MS isotope pattern of parent ion of 11

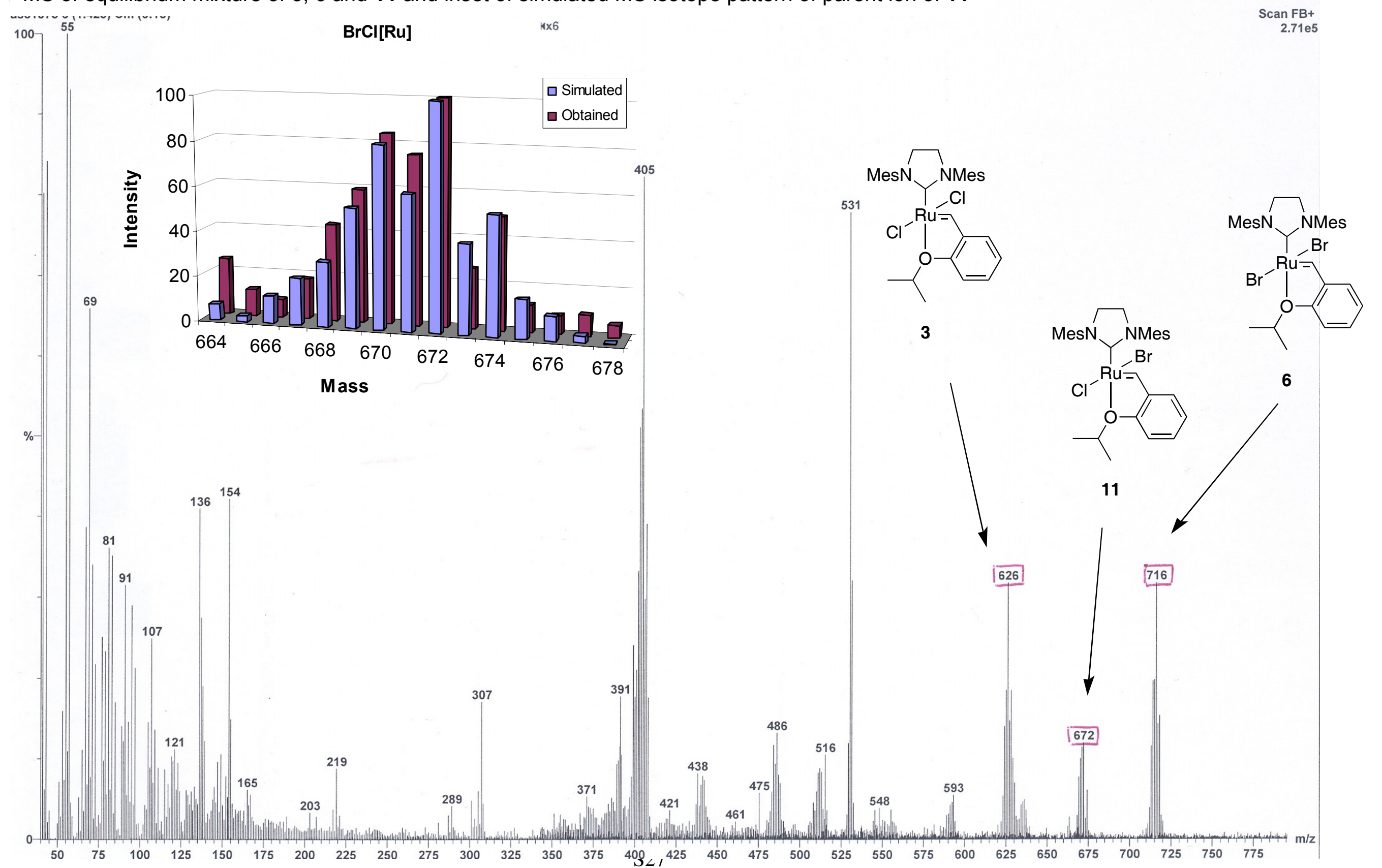

